\title{
Organization of the Drosophila head as revealed by the ectopic expression of the Ultrabithorax product
}

\author{
ACAIMO GONZÁLEZ-REYES and GINÉS MORATA \\ Centro de Biología Molecular (CSIC-UAM), Universidad Autónoma, Canto Blanco, 28049 Madrid, Spain
}

\begin{abstract}
Summary
By using a $h s p 70-U b x$ fusion gene, we have ectopically expressed a $U b x$ product in the embryonic head primordia and studied the developmental effects on the larval head. We find that after high and persistent levels of $U b x$ product, the head is replaced by three $(\mathrm{C} 1, \mathrm{C} 2$ and $\mathrm{C3}$ ) abdominal-like denticle belts. The $\mathrm{C} 2$ and $\mathrm{C3}$ belts are the homeotic transformations of parasegments 1 and 2 , respectively, while the $\mathbf{C 1}$ belt probably derives from the transformation and subsequent fusion of the most anterior procephalic primordia. On the basis of their response to the $U b x$ product and other arguments,
\end{abstract}

we propose that the larval head is made of two genetically distinct components; one is the procephalon and the anterior region of the mandibular lobe, and the other is part of the parasegmental trunk and includes parasegments 1 and 2 . Our results also indicate that most or all the larval head structures derive from precursor cells of ventral origin.

Key words: Drosophila head, heat-shock $U b x$, head involution, homeotic genes.

\section{Introduction}

Much is known about the principal genetic mechanisms controlling early Drosophila development (NüssleinVolhard et al. 1987; Akam, 1987; Ingham, 1988). A cascade of maternal and segmentation genes subdivide the body into parts (metameres), and subsequently the homeotic genes establish the characteristic development (identity) of each metamere. The number of metameres that make up the different body regions and the genes regulating their development are becoming better known. However, relatively little is known about the development of the head. This is partly due to its involution during embryogenesis, a process that obscures the initial disposition of the head primordia (see Turner and Mahowald, 1979; Campos-Ortega and Hartenstein, 1985).

There are two morphologically distinct parts in the embryonic head: the procephalon, located anterior to the cephalic furrow, and the gnathocephalon, which includes the region between the cephalic furrow and the thorax. The number and disposition of head segment primordia is still unclear; a common view (Struhl, 1981a; Jürgens et al. 1986) is that the embryonic head consists of at least six segment primordia: three gnathocephalic lobes (mandibular, maxillary and labial) and three procephalic (hypopharyngeal or intercalary, labral and antennal) ones. This view is mostly based on studies of comparative anatomy (see for instance Anderson, 1972). However, from a detailed study of embryonic head development, Campos-Ortega and
Hartenstein (1985), point out that from morphological evidence the procephalon can be subdivided into only two metameres; the clipeolabrum and the procephalic lobe. Therefore, they suggest that Drosophila head contains two procephalic and three gnathal metameres.

The process of head involution is a principal impediment to studying the development of the head, but it can be prevented in a way that still allows larval development; mutations like extra sex combs (esc) or Polycomb (Pc) cause this effect (Struhl, 1981c, 1983; Sato and Denell, 1985). These mutations produce an overall derepression of homeotic genes (Struhl, 1981c, 1983; Sato and Denell, 1985; Struhl and Akam, 1985), suggesting that the ectopic expression of some of these genes in the head primordia suppresses the function of those head-specific genes responsible for head involution.

In a notable study using esc mutations, Struhl (1983), found a functional hierarchy of homeotic genes: namely, that those specifying the development of posterior regions of the body suppress or reduce the function of those specifying anterior regions. Hence, the presence in a head primordium of a thoracic or abdominal homeotic gene should transform the primordium accordingly. Thus, the number and organization of the transformed head segments in esc ${ }^{-}$embryos may provide significant clues to the original organization of the head.

However, the derepression of homeotic genes in esc or $P c$ mutant embryos occurs relatively late in embryogenesis (Struhl and Akam, 1985; Kuziora and 
McGinnis, 1988a), and probably for this reason the homeotic transformation of the head is incomplete.

By using fusion genes in which the coding region of a homeotic gene is driven by the promoter of the $h s p>0$ gene (Struhl, 1985), it is possible to express different homeotic products all over the body, uniformly and at any time in development (Gibson and Gehring, 1988; Kuziora and McGinnis, 1988b; Mann and Hogness, 1990; González-Reyes et al. 1990; González-Reyes and Morata, 1990). At least for Antennapedia (Antp) and Ultrabithorax $(U b x)$, it has been shown that, if their products are present in the head primordia in embryos of 4 to $8 \mathrm{~h}$ of age, the involution of the head is partially or completely prevented and some head primordia are homeotically transformed (Gibson and Gehring, 1988; Gonzalez-Reyes and Morata, 1990). The time of heat shock is well before normal involution takes place at 10 to $16 \mathrm{~h}$ of development (Campos-Ortega and Hartenstein, 1985), strongly suggesting that the ectopic expression of $A n t p$ or $U b x$ does not interfere with the mechanics of the involution, but with the genetic machinery determining it.

In this paper, we examine the response of the different head regions to the ectopic presence of the $U b x$ protein. To manipulate $U b x$ expression, we have used the $h s p 70-U b x$ gene (called HSU, GonzálezReyes and Morata, 1990). The experiments have been performed in (a) embryos containing a normal set of homeotic genes, (b) mutant embryos for Deformed $(D f d)$ and Sex combs Reduced (Scr), two homeotic genes determining head development, (c) mutant embryos for even-skipped (eve) and fushi tarazu (ftz), pair-rule genes expressed in part of the head and (d) mutant embryos for empty spiracles (ems) and buttonhead (btd), gap-like genes specific for head development (Cohen and Jurgens, 1990; Finkelstein and Perrimon, 1990). We conclude that the head can be subdivided into two regions, one belonging to the parasegmental trunk and the other anterior to it, and that these two regions respond differentially to the inappropriate expression of $U b x$.

\section{Materials and methods}

\section{Mutant stocks}

All the mutations used in this work have been described previously. $D f d^{\mathrm{Tw} 21}$ is a null allele of the Deformed gene (Merrill et al. 1987). The mutation Antp ${ }^{\mathrm{Ns}+\mathrm{RC} 3}$ (Strubl, 1981b) completely eliminates Antp function, and the null mutation $\mathrm{Scr}^{\mathrm{C1}}$ (Struhl, 1982) eliminates $\mathrm{Scr}$ function. The chromosome $D f(3 R) R X 1$ is an aneuploid segregant of $T p(3 R) R X I$ with a breakpoint at the $D f d$ gene, in which the ANT-C genes proximal to $D f d$ have been transposed to the region 98F1,2 (Hazelrigg and Kaufman, 1983). The $D f(3 R) R X 1$ chromosome therefore, will lack all ANT-C genes proximal to and including $D f d$. In some cases, like for example the double mutant combination $S_{C r}{ }^{C 1} A n t p^{N S+R C 3}$ or the $D f(3 R) R X 1$, the ANT-C mutations were recombined with $A b d-B^{M I}$, a null allele of $A b d o m i n a l-B$ (Casanova $e t a l$. 1986). This permitted us to distinguish the homozygous embryos from the heterozygous ones, because the former, being homozygous for $A b d-B^{M 1}$ will, after heat shock, develop an extra denticle belt in parasegment 14 (GonzálezReyes and Morata, 1990).

The mutations in the gap-like genes $e m s^{9 G}$ and $b t d^{X G 81}$ have been described in Cohen and Jürgens, 1990; Finkelstein and Perrimon, 1990.

The HSU construct was described in Gonzallez-Reyes et al. (1990) and basically consists of the $h s p 70$ promoter region linked to Ubx RNA Ia, one of the $U b x$ products (Kornfeld $e t$ al. 1989). We have used two lines, HSU-11 on the second chromosome, and HSU-42 on the third, which otherwise behave equally.

\section{Heat-shock experiments}

Embryos of $2 \mathrm{~h} 50 \mathrm{~min}-3 \mathrm{~h}$ old were selected under the dissecting microscope using morphological markers (stage 6 of Campos-Ortega and Hartenstein, 1985). Subsequently they were transferred to a water bath at $25^{\circ} \mathrm{C}$ to allow them to develop until the appropriate age and then heat shocked at $36^{\circ} \mathrm{C}$ for the desired length of time. In experiments where timing was not so critical, embryos were collected after $2 \mathrm{~h}$ of egg-laying and heat shocked at $36^{\circ} \mathrm{C} 4 \mathrm{~h}$ later (most of them are $4-6 \mathrm{~h}$ old). After the treatment, the embryos were allowed to resume development until the end of embryogenesis.

\section{Preparation of the larval cuticles}

To prepare the embryonic cuticle, we followed the standard methods as described in González-Reyes and Morata (1990).

\section{Results}

\section{Outline of the configuration and origin of the normal} head structures

Cephalogenesis is a complex sequence of movements resulting in, first, the transport of head's blastoderm anlagen to the more anterior and ventral positions displayed at the germ band stage (Technau and Campos-Ortega, 1985) and, second, the involution of the head, which begins at stage 14 (Campos-Ortega and Hartenstein, 1985) and is intimately linked to the atrium formation. The result is the inclusion of the clypeolabrum, part of the labrum and the three gnathal segments into the atrium.

The disposition of the different head primordia at the extended germ band stages and the position of the differentiated structures they generate in the larval head are shown schematically in Fig. 1. In our analysis of the development of the head after ectopic expression of the $U b x$ product, we have used the presence and/or position of these specific cuticular markers to assign their respective primordia. We have paid particular attention to the markers indicated in Table 1.

\section{Effect of inappropriate Ubx expression in the head primordia}

We have performed two series of experiments to study (1) the response of the head primordia to a high, persistent expression of $U b x$ product during the period when segmental structures are determined, and (2) the effect of brief pulses of $U b x$ protein at different stages of embryonic development. 
A

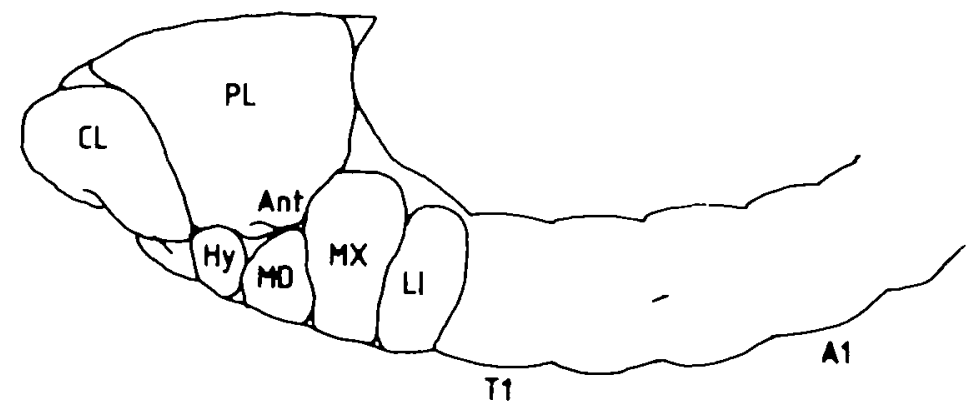

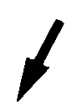

B

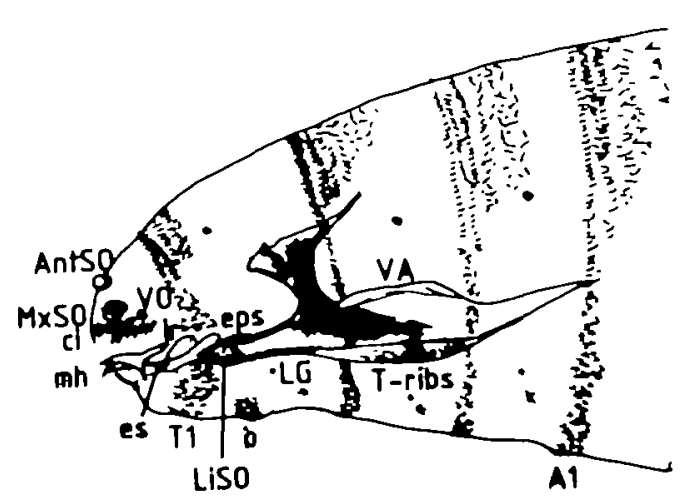

$1+$ HS

C

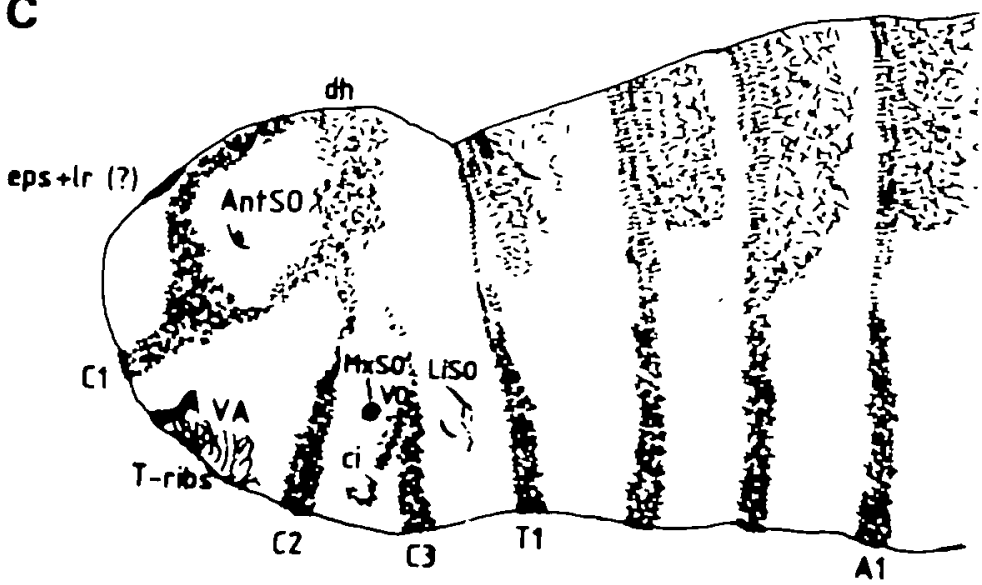

Fig. 1. Position of different head components in (A) embryo at the extended germ band stage, (B) wild type embryo, (C) HSU embryo after multiple heat shock. Abbreviatishock. Abbreviations as in Table 1.

Table 1. Segmental origin of larval head structures (as in Jurgens et al. 1976)

\begin{tabular}{llll}
\hline Structure & Abbreviation & Segment & Head region \\
\hline Labial sense organ & LiSO & Labial & Gnathocephalon \\
Cirri & $\mathrm{ci}$ & Maxillary & \\
Mouth hook & $\mathrm{mh}$ & & \\
Ectostomal sclerite & es & & \\
Central part of the & MxSO' & & \\
maxillary sense organ & & & \\
Ventral arm & VA & Mandibular & \\
T-ribs & T-ribs & & \\
Lateralgräte & LG & & \\
Hypopharingeal organ & HO & Intercalary & Procephalon \\
Antennal sense organ & AntSO & Antennal & \\
Epistomal sclerite & eps & Labral & \\
Labrum & li & & \\
\hline
\end{tabular}

(1) Persistent expression of Ubx results in the appearance of three abdominal-like denticle belts To assure a high level of $U b x$ protein during all the critical stages of development (Gonzalez-Reyes and Morata, 1990), we took stage 6-7 HSU embryos and then heated at $36^{\circ} \mathrm{C}$ for $20 \mathrm{~min}$ at each of the ages of 4,6 and $8 \mathrm{~h}$. This treatment does not produce significant embryonic lethality; most embryos develop to hatch as first instar larvae with profound alterations in head and thoracic morphology.

Most of these larvae present three abdominal belts with A1 identity in the place of the head. A typical case of transformation of the thoracic and head regions is shown in Fig. 2. The three thoracic segments are almost completely transformed into replicas of the first abdominal segment; ventrally there are three belts of 


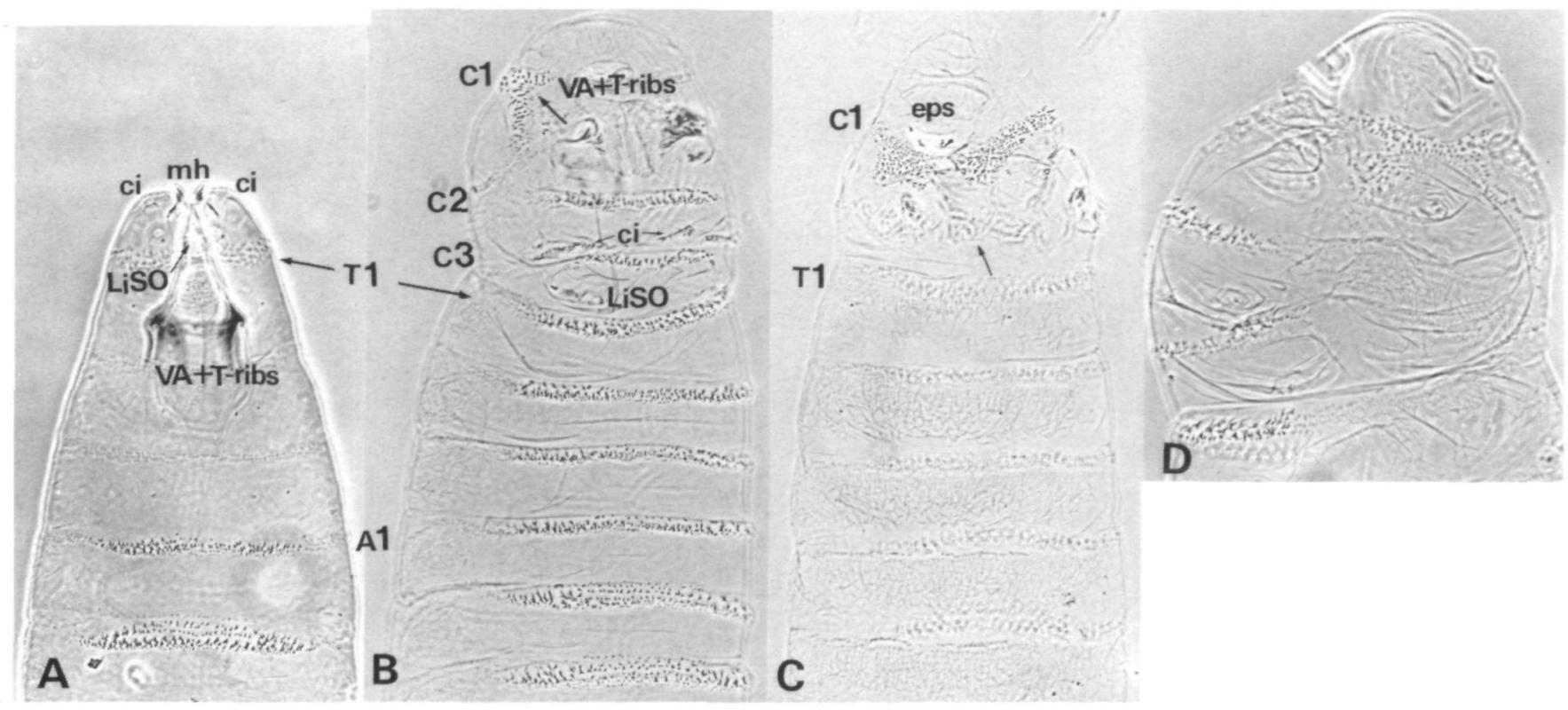

Fig. 2. Effect of a multiple heat shock on the head. (A) Ventral aspect of the head, thorax and part of the abdomen of a wild type larva. Most of the head structures are invaginated, the mouth hooks occupying the most anterior position. The $\mathrm{T} 1$ and $\mathrm{A} 1$ denticle belts are indicated. (B) Ventral aspect of a similar portion of the body of a heat-shocked larva. Note the appearance of three $(\mathrm{C} 1, \mathrm{C} 2$ and $\mathrm{C} 3)$ cephalic denticle belts situated anterior to the thorax due to the failure of head involution. The three cephalic belts and also the three thoracic ones show characteristics of the A1 segment. In the head segments and in spite of the abdominal transformation, some head elements still remain and can be assigned to the primordia generating the belts. The LiSO is in the same segment as C3 and the cirri are in C2. The situation in C1 is more complicated due to the peculiar structure and disposition of this belt. Note that it is bifurcated (arrow) and localized laterally. This makes it difficult to assign the segmental origin of the head elements (T-ribs, VA, eps) associated with this belt. (C) Dorsal side of the same larva to show that the $\mathrm{Cl}$ belt extends a long way into this side, even though it differentiates denticles of ventral type, like those of $\mathrm{C} 2$ and $C 3$. The picture also shows that there is only one group of dorsal spinules (arrow). (D) Lateral view at a higher magnification of a heat shocked larva to show the three ventral denticle belts and the single dorsal one. Note that $\mathrm{C} 1$ and $\mathrm{C} 2$ are clearly connected to the spinule group.

denticles with the typical pattern of the first abdominal (A1) segment, dorsally there are three belts of spinules (Fig. 2) exhibiting an abdominal pattern.

On the ventral side and anterior to the transformed thoracic segments, we observe three additional abdominal-like denticle belts that we have called $\mathrm{C} 1, \mathrm{C} 2$ and $\mathrm{C} 3$ (González-Reyes and Morata, 1990). Although their denticle pattern is not a perfect example of $A 1$ pattern, we assume that it is A1 for two reasons, (1) the homology with the adjacent thoracic transformation and (2) because the connection between ventral denticles and dorsal spinules is the characteristic one for A1, being different from the other abdominal segments (see Fig. 2 legend). Also by homology with the other abdominal segments, we assume that the denticle belts correspond to the anterior compartments and mark the anterior border of the segment. The dividing line separating anterior from posterior compartments should run approximately through the middle of the naked region between belts (Struhl, 1984), while the posterior border coincides with the anterior margin of the next belt.

Intriguingly, we find that, unlike the thorax in which each transformed segment produces ventral denticles and dorsal spinules, in the transformed head the three transformed primordia give rise to only one belt of dorsal spinules instead of the expected three (Fig. 2). This suggests that there may be only one dorsal primordium or, if there are several, they have fused to form a single group. The $\mathrm{C} 1$ and $\mathrm{C} 2$ ventral belts are both connected to the single group of dorsal hairs supporting the hypothesis of fusion.

The transformation of the $\mathrm{C} 1$ belt is remarkable in several respects. First, $\mathrm{C} 1$ morphology is different and more complex than that of $\mathrm{C} 2$ and $\mathrm{C} 3$; it is formed by two separate branches of ventral denticles that surround the epistomal sclerite (eps) (Fig. 2) and an unidentified structure, possibly the labrum (lr). The two branches are located laterally and are frequently bifurcated. They often show conflicting polarities. Second, many of the ventral denticles are in a dorsal position and are often connected to the single group of dorsal spinules (Fig. 2). A line separating dorsal from ventral structures can be drawn as shown in Fig. 3. Assuming that the heat shock has completely prevented the involution of the head and that the position of the different structures reflects the original disposition of the primordia, this suggests that the genetic mechanism establishing the distinction between dorsal and ventral primordia runs asymmetrically through the embryonic head.

The position of the head structures in the trans- 

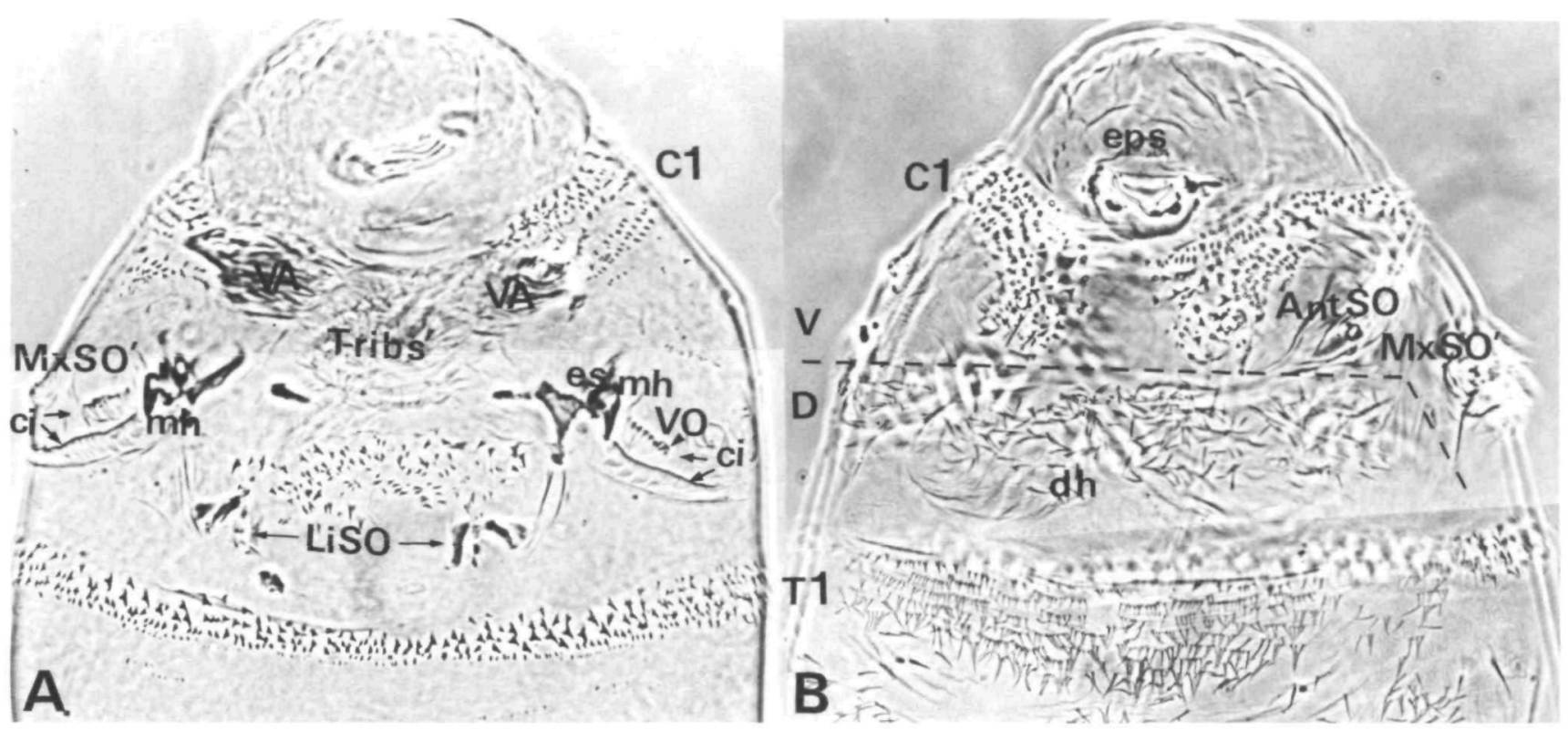

Fig. 3. Ventral (A) and dorsal (B) aspects of the head of a larva after a mild heat shock. A number of head structures, MxSO', ci, VO, mh, es, VA, T-ribs and LiSO (split in two halves) can be recognized in the ventral side, but in the dorsal side only the AntSO (which appears in lateral position) and the eps. Note also that the C1 belt extends to the dorsal side. Thus, most head structures appear to derive from ventral cells. The line separating primordia generating ventral ( $V$, denticles) and dorsal (D, spinules) segmental structures runs across the dorsal side of the embryo (as illustrated in B). dh dorsal hairs anterior to T1.

formed larvae is also significant. Although most of them are missing, those that remain always appear on the ventral side of the larvae, associated with the denticle belts. This also occurs in cases of milder heat shock treatments $(30 \mathrm{~min}$ or $1 \mathrm{~h})$ in which many head structures remain, and strongly suggests that most or all the larval head derives from ventral precursor cells (Fig. 3). This is consistent with the observation (Anderson et al. 1985) that dorsal mutant larvae, in which the ventral structures are replaced by dorsal ones, lack most of the head.

Head elements appear in fixed positions so that they can be respectively associated with one of three belts. In the cases of the $\mathrm{C} 2$ and $\mathrm{C} 3$, it is easy to identify the cephalic primordia that generate them. The $\mathrm{C} 2$ belt nearly always contains cirri (ci), mouth hooks (mh) and the central part of the maxillary sense organs $\left(\mathrm{MxSO}^{\prime}\right)$, structures that derive from the maxillary segment (Jurgens et al. 1986; McGinnis et al. 1990). The C 3 belt can also be identified as the result of the transformation of the labial segment as it is associated with the labial sense organ (LiSO), which appears subdivided into two halves.

The classification of the $\mathrm{C} 1$ belt is much more difficult than for the previous two; structures like the antennal sense organs (AntSO), epistomal sclerite (eps), labrum (Ir), ventral arms (VA) and T-ribs appear associated with this belt or are anterior to it. According to previous fate maps, they originate from different segments, labral, antennal and mandibular. As we show below, there is the possibility that the $\mathrm{C} 1$ belt is a composite structure resulting from the fusion of several transformed primordia.

We have tried to test the hypothesis of fusion by studying the evolution in heat-shocked embryos of the spots of en expression (DiNardo et al. 1985) in the procephalon. A fusion of primordia could be reflected in the en expressing cells tending to form a single group. Experimental embryos of $4 \mathrm{~h}$ of age were heat shocked for 1 and $1 / 2 \mathrm{~h}$ and fixed $4 \mathrm{~h}$ later, after germ band retraction. The comparison the en patterns of heatshocked and control embryos shows no significant alteration. There is the possibility that fusion of procephalic primordia occurs later and has escaped our notice.

Taken together, these observations suggest that ectopic $U b x$ expression in the head causes homeotic transformations in both the gnathocephalic segments and the procephalon, although the extent to which the latter is affected remains unclear. These homeotic transformations probably prevent the phenomenon of head involution, so that the head primordia remain in their original position as illustrated in Fig. 1

\section{(2) Head primordia respond differentially to Ubx overexpression}

We have tried to correlate the defects observed after the heat treatment with the age of the embryos and the time course of head involution (see Turner and Mahowald, 1979 for a detailed description of the process). To this effect, $3 \mathrm{~h}$ embryos (stage 6) were grouped in batches and given a 30 min heat shock at 3 , 


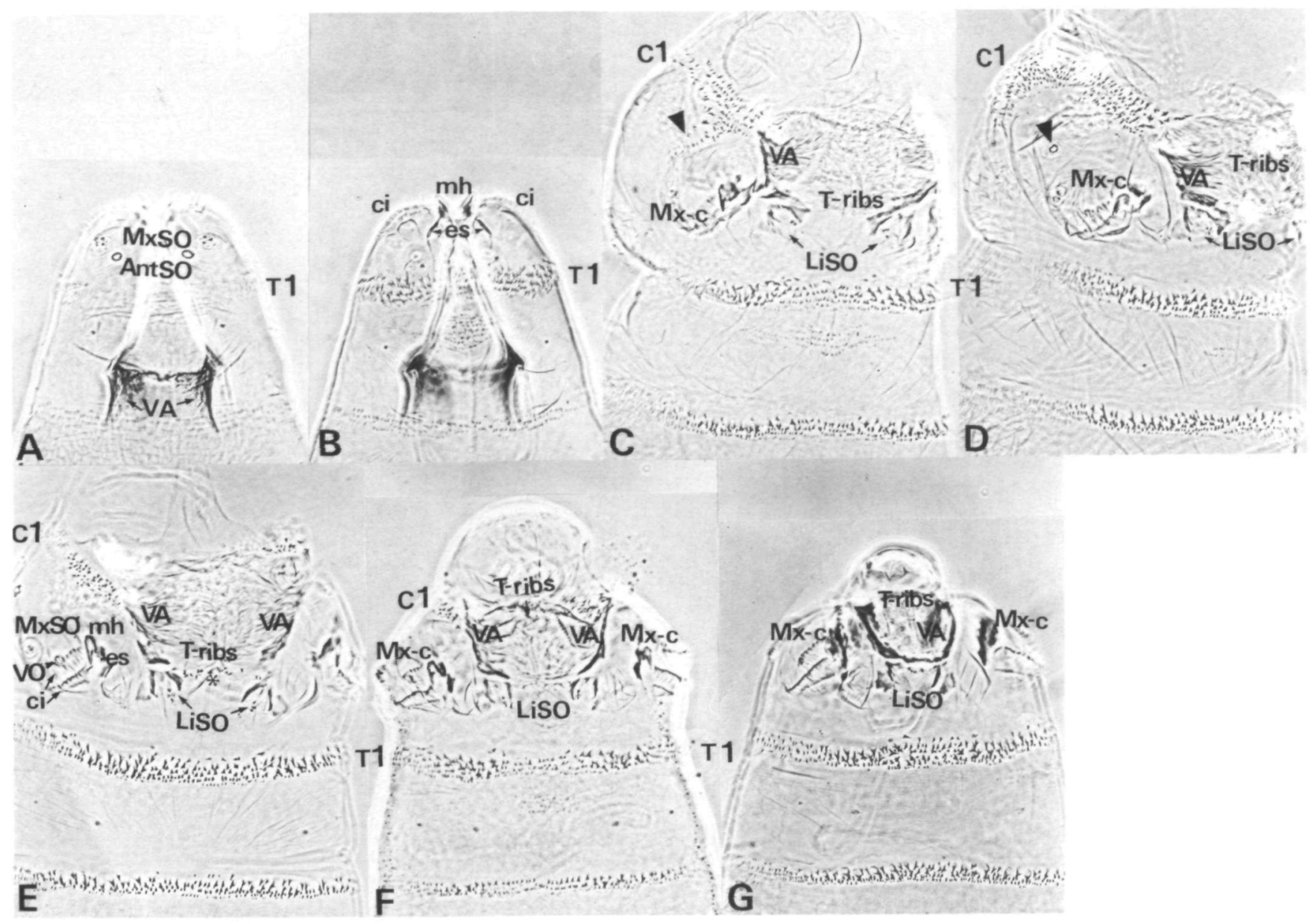

Fig. 4. Temporal response to a heat shock. (A) and (B) Dorsal and ventral views of a wild type head to indicate the position of different head elements scrutinized in heat-shocked larvae. Nomenclature as in previous figures. Mx-c: Maxillary complex. (C) Effect of a $30 \mathrm{~min}$ heat shock to a $3 \mathrm{~h}$ embryo; the involution of the head is prevented, but there is only one belt, $\mathrm{C} 1$. Different head components (VA, T-ribs, Mx-c and LiSO) fail to fuse and appear distributed between C1 and the transformed T1. The AntSO is notoriously lacking and is replaced by a small row of denticles (arrowhead). (D) Effect of the same treatment to a $5 \mathrm{~h}$ embryo. It is like in $3 \mathrm{~h}$ embryos with the difference that the AntSO is now present (arrowhead). (E) Same treatment to a $6 \mathrm{~h}$ embryo. The significant difference is the presence of some few denticles of abdominal type $\left(^{*}\right)$ indicating a slight transformation of the $\mathrm{C} 2$ primordium. The components of the $\mathrm{Mx}-\mathrm{c}$ (ci, mh, VO, es and $\mathrm{MxSO}^{\prime}$ ) are indicated. (F) Head of a treated $7 \mathrm{~h}$ embryo. The $\mathrm{C} 1$ belt is less developed and some of the head components that normally fuse, like VA and LiSO, are now closer than in previous cases, indicating that head involution has not been completely suppressed. Also, the $\mathrm{Mx}-\mathrm{c}$ is located more anteriorly. (G) Head of a treated $9 \mathrm{~h}$ embryo. The $\mathrm{C} 1$ belt is very reduced (the remaining part is on the dorsal side and therefore not visible in the photo) and the VA and LiSO are now much closer and partially fused. The $\mathrm{Mx}-\mathrm{c}$ is near the tip of the head, showing that the involution of the head has largely taken place.

$5,6,7,8,9$ or $12 \mathrm{~h}$ of development. Some batches were also given longer treatments of $1 \mathrm{~h}$.

In $3 \mathrm{~h}$ treated embryos head involution is partially prevented, exhibiting in the most anterior region a curved abdominal-like denticle belt resembling $\mathrm{C} 1$ in every aspect. Ventrally, the mh are present, associated with the ectostomal sclerite (es), the two rows of cirri, the ventral organ (VO) and, more laterally, with the central part of the maxillary sense organ $\left(\mathrm{MxSO}^{\prime}\right)$. The two halves of the LiSO are situated in between the maxillary complexes ( $\mathrm{Mx}-\mathrm{c}$, formed by $\mathrm{mh}$, es, ci, VO, and $\mathrm{MxSO}^{\prime}$ ). More anteriorly, a pair of irregular structures that could correspond to the LG are associated with the ventral arms (VA) and the T-ribs $(\mathrm{T})$, at the border of $\mathrm{Cl}$. These embryos lacked the antennal sense organs (AntSO), replaced by two or three rows of denticles (Fig. 4).

Heat-shocked $5 \mathrm{~h}$ embryos showed similar but not identical alterations in head morphology. A significant difference is that the AntSO is now present in the dorsolateral part of the head and surrounded by some denticles and hairs, (Fig. 4). Longer treatments (1 h) given to these embryos produced a new denticle belt interposed between the two maxillary complexes and the VA+T-ribs (Fig. 4), indicating a different segmental provenance of these structures. Laterally this new 
belt connects with the group of dorsal hairs anterior to T1. This belt corresponds to the homeotic transformation of the maxillary segment as suggested by the disposition of the head structures that remain present; $\mathrm{VA}$ and T-ribs anterior to the belt are known to belong to the mandibular segment (Jürgens et al. 1986), while the $\mathrm{MxSO}^{\prime}, \mathrm{ci}, \mathrm{VO}, \mathrm{mh}$ and es are close or posterior to it. Sometimes, and in particular in the longer heat shocks, we observed a small group of abdominal denticles in the position corresponding to the $\mathrm{C} 3$ belt described above, although never as well developed as C2. In addition, the position of the AntSO depends on the length of the pulse, moving toward the dorsal side in the longer treatments and eventually occupying the dorso-lateral location shown in Fig. 4.

A 30 min heat shock given to $6 \mathrm{~h}$ embryos produces an effect in the head similar to that seen for $5 \mathrm{~h}$ embryos, with the differencè that the $\mathrm{C} 2$ belt is always present even after $30 \mathrm{~min}$ heat shock. Increasing the duration of the pulse to 60 or $90 \mathrm{~min}$ produces stronger transformations, although never reaching the complete effect seen in $5 \mathrm{~h}$ heat-shocked embryos.

The morphological effects of a $30 \mathrm{~min}$ heat shock to 7 , 8 and 9 h embryos were much less pronounced. The number of head structures remaining is greater and the involution of the head is partial. There is no evidence for homeotic transformation of $\mathrm{C} 2$ and $\mathrm{C} 3$ segments and the transformation observed in $\mathrm{C} 1$ is reduced; there were less dorsal hairs in the group anterior to $\mathrm{T} 1$, and the dorsal denticle belts were smaller. In $7 \mathrm{~h}$ embryos the two halves of the LiSO have approached each other, in correlation with the migration of the labial lobes during head involution (Turner and Mahowald, 1979. Fig. 4) indicating that part of the process of head involution has taken place, and in $8 \mathrm{~h}$ embryos they appear fused to form a single structure. $9 \mathrm{~h}$ old (late stage 12) embryos showed some displacement of head structures and presence of a few ventral denticles belonging to $\mathrm{C} 1$; the mandibular derivatives are located at the origin of the invagination, and the eps and labrum close to the LiSO in the opening of the atrial cavity (Fig. 4). This reflects the late events of head involution (Campos-Ortega and Hartenstein, 1985). Embryos heat shocked at $12 \mathrm{~h}$ showed no detectable differences with the wild type.

\section{Comparison of $H S U$ with esc embryos}

It is of interest to compare the head of HSU embryos with those of esc mutant embryos in which a number of homeotic genes are derepressed (Struhl, 1983; Struhl and White, 1985). In all cases, the transformation is weaker in esc mutants, even if there are several doses of the BX-C; at most there are two abdominal-like segments, one with the same structure of the $C 1$ segment and the second that we identify as $C 2$ (see for example Fig, 2 A,B in Struhl, 1983). The fact that the $\mathrm{C} 1$ belt looks alike in HSU and esc embryos is significant for it indicates that its peculiar structure is an inherent property of the primordium or primordia and is unrelated to the heat shock treatment or the HSU stocks.
Homeotic, segmentation and maternal genes required in head development

Since in HSU embryos the failure of head involution permits us to study and define better the original components of the larval head, we have taken advantage of this to analyze the role of several developmental genes in the head.

\section{(1) Homeotic genes}

We have examined mutations of two homeotic genes; $D f d$ and $S c r$. The gene $D f d$ is expressed in the mandibular and maxillary segments (McGinnis et al. 1990). In HSU $D f d^{-}$embryos the transformation of the head primordia produces $\mathrm{C} 1, \mathrm{C} 2$ and $\mathrm{C} 3$ belts as in HSU $D d^{+}$, but maxillary structures like cirri and mh are missing. However, the $\mathrm{MxSO}^{\prime}$ remains (Fig. 5). It seems that the major role of $D f d$ in the larval head is the differentiation of cirri and mouth hooks. This is consistent with the finding that only these organs appear after ectopic expression of the $D f d$ gene (Kuziora and McGinnis, 1988b), and with the phenotype of $D f d$ mutations (McGinnis et al. 1990).

The gene $S c r$ specifies the development of the labial and prothoracic segments (Wakimoto and Kaufman, 1981; Struhl, 1983). HSU Scr ${ }^{-}$embryos are like those $\mathrm{SCr}^{+}$, with the difference that the LiSO are missing and there is a duplicate of the $\mathrm{MxSO}^{\prime}$ in the labial segment (Fig. 5), which does not contain $D f d$ activity (McGinnis et al. 1990). This latter observation may be of interest as the $\mathrm{MxSO}^{\prime}$ also appears in $D f d^{-}$embryos. Thus, the $\mathrm{MxSO}^{\prime}$ may be a component of the 'ground' pattern, that is, the identity established in the absence of homeotic information.

In an attempt to identify other possible ANT-C genes necessary for head development, and especially the $\mathrm{C} 1$ primordium, we heat shocked HSU embryos homozygous for $D f(3 R) R x 1$. This deficiency removes the proximal portion of the ANT-C, from a breakpoint in Dfd that inactivates the gene (see Materials and methods, Hazelrigg and Kaufman, 1983). Therefore, HSU-Df(3R) Rxl embryos are deficient for lab, proboscipedia, zerknüllt and mutant for $D f d$ (Mlodzik et al. 1988; Kaufman et al. 1990). Given the correlation between the genetic order within the ANT-C and the pattern of expression of the genes (see the review by Kaufman et al. 1990), those located more proximally in the complex would be expected to be involved with the development of the anterior cephalic regions. We find that these embryos, after heat shock, are indistinguishable from those only deficient for $D f d$. However, there was the possibility that head structures depending on some of these genes, such as labial are phenotypically suppressed by $U b x$ and therefore not susceptible to our analysis. To check on this possibility, in some experiments we gave mild heat shock treatments in order to produce HSU $D f(3 R) R X 1$ larvae that still retain a large number of head markers. They were still indistinguishable from those that were HSU $D f d^{-}$, suggesting that proximal ANT-C genes contribute little or nothing to the larval head. Thus, it seems that the genes specifying 


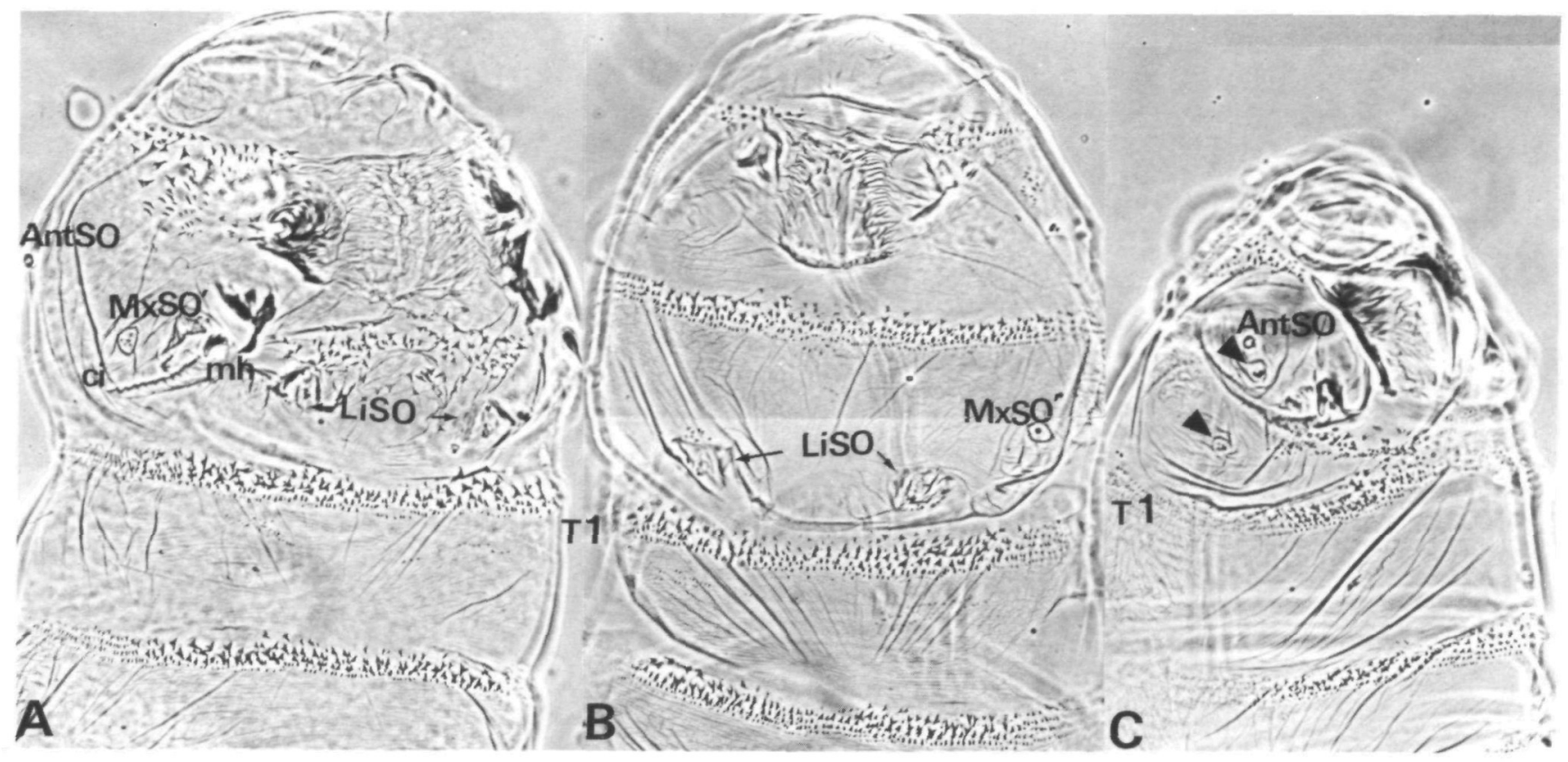

Fig. 5. Comparison of heads of $\mathrm{HSU}$ (A), HSU $D f d^{-}$, (B) and HSU Scr ${ }^{-}$(C), larvae. In B, the lack of $D f d$ function results in the lack of cirri and $\mathrm{mh}$, although the $\mathrm{MxSO}^{\prime}$ and the $\mathrm{LiSO}$ are present. In $\mathrm{C}$, the defect in $S c r$ produces the lack of the LiSO but the $\mathrm{MxSO}^{\prime}$ is duplicated (arrowheads).

head primordia anterior to the $D f d$ domain are not located in the ANT-C.

\section{(2) Pair-rule genes}

The pair-rule genes eve and $f t z$ are not expressed anterior to the cephalic furrow, affecting only gnathal, thoracic and abdominal segments (reviewed in Akam, 1987). To characterize further the effect of $U b x$ expression in the head segments, we have heat induced the HSU gene in $e v e$ and $f t z$ mutants. In $e v e^{-}$pair-rule embryos, parasegments $1,3,5$, etc. are missing. In the head of HSU eve $e^{-}$mutants, we find (Fig. 6) that the $\mathrm{C}_{2}$ belt is lacking but $\mathrm{C} 1$ and $\mathrm{C} 3$ look as in HSU eve ${ }^{+}$ embryos. Also, the structures associated with $\mathrm{C} 1$, like T-ribs and VA, are present. This is noteworthy for it shows that all these elements derive from material anterior to parasegment $\mathbf{1}\left(\mathrm{Md}_{\mathrm{p}}-\mathrm{Mx}_{\mathrm{a}}\right)$. It is also of interest that in spite of the lack of $\mathrm{C} 2$ belt, cirri and $\mathrm{MxSO}^{\prime}$ remain, indicating that they derive from the posterior compartment of the maxillary segment (parasegment 2, $\mathrm{Mx}_{\mathrm{p}}-\mathrm{Li}_{\mathrm{a}}$ ).

The previous conclusion is reinforced by the phenotype of HSU $\mathrm{ftz}^{-}$embryos, which lack cirri, $\mathrm{mh}$ and the C3 belt, that is, $\mathrm{Mx}_{\mathrm{p}}-\mathrm{Li}_{\mathrm{a}}$, or parasegment 2 . The LiSO remains, indicating that it belongs to parasegment 3 $\left(\mathrm{Li}_{\mathrm{p}}-\mathrm{T1}_{\mathrm{a}}\right.$, Fig. 6).

\section{(3) Gap-like head-specific genes}

Based on the comparison of the phenotypes of $b c d^{-}$ and $h b^{-}$embryos, the existence of $b c d$-dependent head specific genes acting anterior to the $h b$ domain, was postulated (Driever et al. 1989). Recently, three candidates for such genes, ems, orthodenticle (otd) and btd, have been identified (Cohen and Jurgens, 1990; Finkelstein and Perrimon, 1990). Since mutations in these genes remove different and overlapping sets of procephalic and gnathal (mandibular) segments, we studied the HSU-induced transformations in them. In the case of otd, the larval cuticle differentiates poorly after heat shock and therefore we have not considered these embryos.

buttonhead. These embryos have been described as lacking the mandibular, intercalary and antennal segments (Cohen and Jurgens, 1990). Quite unexpectedly, we find (Fig. 7) that HSU btd embryos show a well developed $\mathrm{C} 1$ belt similar to those of HSU otherwise normal embryos. The only significant difference with the normal $\mathrm{C} 1$ belt is the lack of the lateral bifurcation surrounding the antennal organ that connects with the dorsal spinules. This makes the $\mathrm{C} 1$ belt to look more like the $\mathrm{C} 2$ and $\mathrm{C} 3$ belts and suggests that in btd embryos the $\mathrm{Cl}$ may derive from a single primordium.

The previous observations suggest that the $\mathrm{C} 1$ belt incorporates little material from the mandibular, intercalary and antennal segments and therefore originates predominantly from the very anterior part of the procephalon. The T-ribs, the VA and the $\mathrm{C} 2$ belt $\left(\mathrm{Mx}_{\mathrm{a}}\right)$, are missing (Fig. 7), but the cirri and mouth hooks $\left(\mathrm{Mx}_{\mathrm{p}}\right)$ are present. This indicates that the btd mutants remove, in addition to more anterior segments, at least part of the anterior compartment of the maxillary segment. Therefore the posterior border of the btd domain is not a segmental boundary (Cohen and Jurgens, 1990). Our results suggest that it is parasegmental and occurs at the intersection of parasegments 1 and 2. However, the observation of Cohen and Jurgens, 

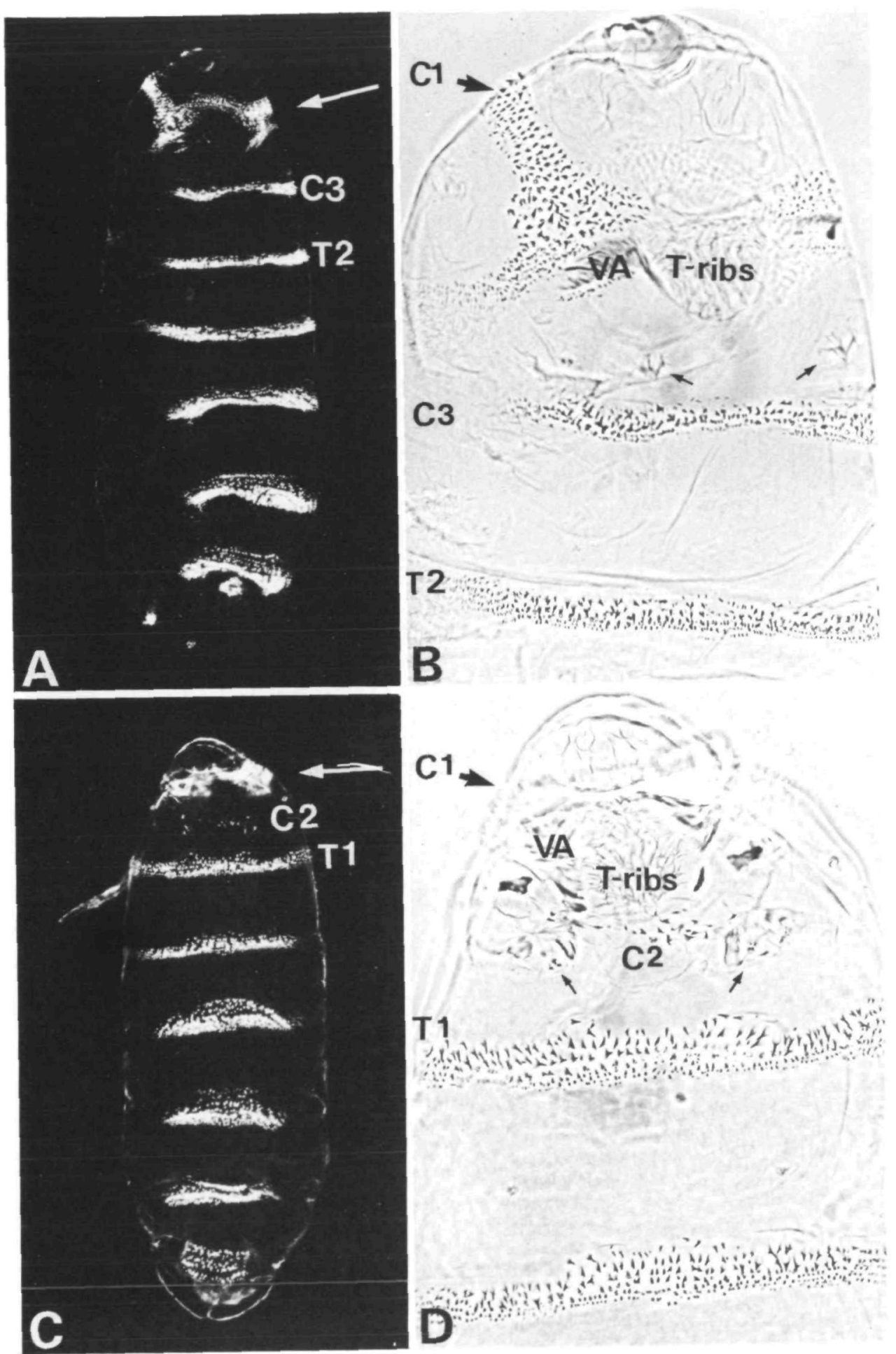

Fig. 6. Effect of the heat shock in the head of HSU $e v e^{-}\left(\mathrm{A}\right.$ and B) and HSU $f t z^{-}$ ( $C$ and $D$ ) embryos. In eve mutant heads, the $\mathrm{C} 1$ belt and T-ribs and VA develop as in normal HSU embryos, the $\mathrm{C} 2$ belt is missing but cirri and $\mathrm{mh}$ are present (arrow). In $f t z$ mutants, the $\mathrm{C} 1$ and $\mathrm{C} 2$ belts develop and also mandibular (T-ribs and VA) elements. The $\mathrm{C} 3$ belt never appears but the LiSO is frequently present (the arrows show the two halves of the LiSO).

(1990) that in btd there is a wg stripe in the maxillary segment suggests that there may be some maxillary anterior compartment material remains in btd mutants.

empty spiracles. These mutants lack the intercalary, antennal and preantennal primordia (Cohen and Jürgens, 1990). In HSU ems ${ }^{-}$embryos, the C2 and C3 denticle belts and pattern elements associated with them such as cirri, mh, MxSO' and LiSO develop as in normal HSU embryos. Also, mandibular structures like T-ribs and ventral arms are present. However, the $\mathrm{Cl}$ belt is very reduced in size (Fig. 7), indicating that material missing in the mutant contributes substantially to this belt. The small $\mathrm{C} 1$ belt of these embryos could perhaps represent the contribution of the mandibular segment. The distinct behavior of the $\mathrm{C} 1$ belt with 


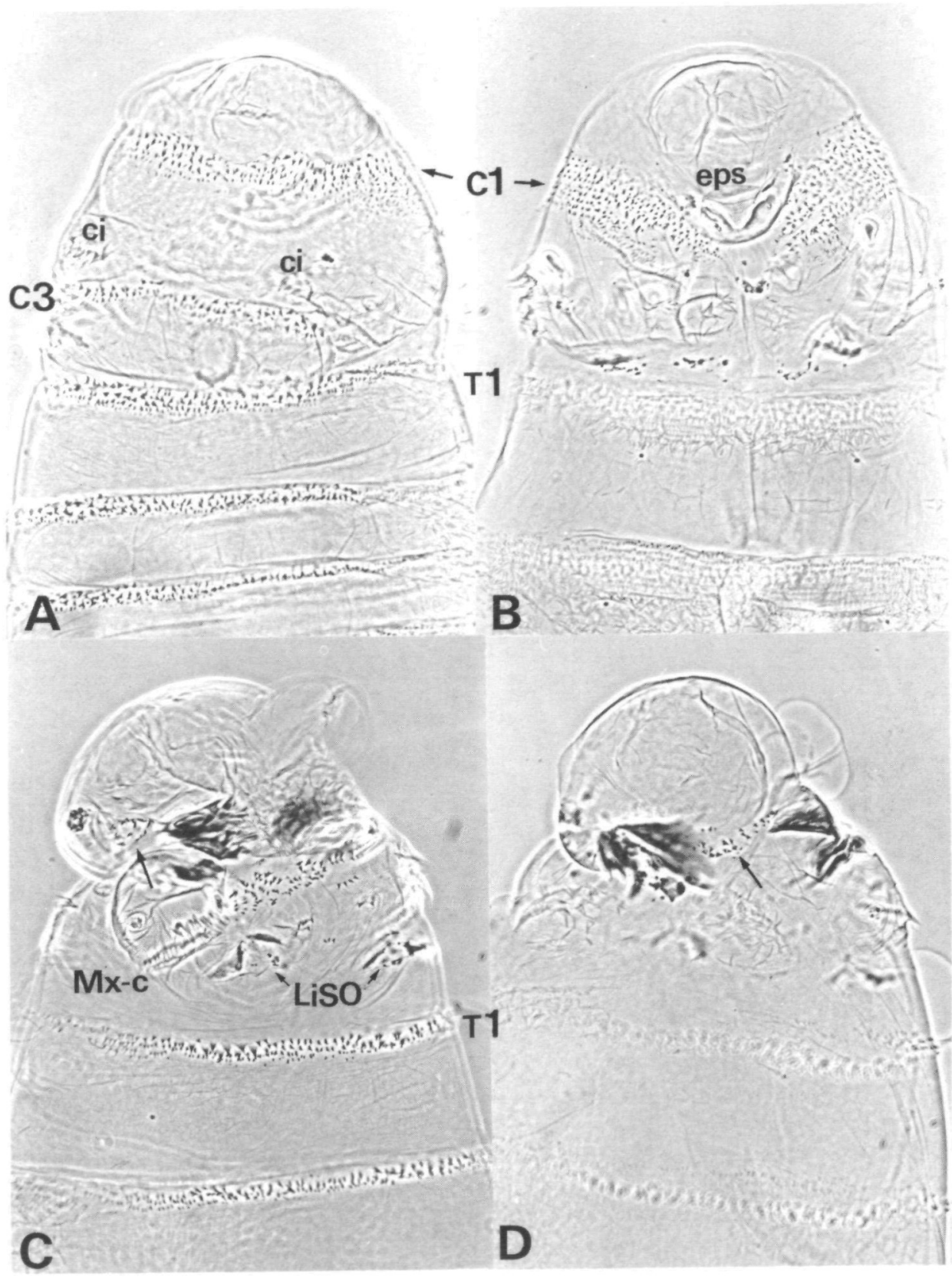

Fig. 7. Ventral and dorsal views of buttonhead (A and $\mathrm{B}$ ) and empty spiracles (C and D) mutant heads after heat-shock treatment. In btd the $\mathrm{C} 1$ belt is of normal size although it lacks both the lateral bifurcation normally present in HSU embryos and the conflicting polarity of the denticles. Also mandibular structures like the T-ribs and the VA are lacking. The $\mathrm{C} 2$ belt is missing and the $\mathrm{C} 3$ is unaffected. Note the presence of cirri that mark the posterior compartment of the maxillary segment. Dorsally, the eps is present and the group of dorsal hairs reduced. In ems, the $\mathrm{C} 1$ belt is much reduced to some few denticles in the dorsolateral side (arrows). Although not obvious from the picture, the $\mathrm{C} 2$ and $\mathrm{C} 3$ belts develop as in normal HSU embryos and also the organs associated with them (T-ribs and VA, Mx-c, LiSO). respect to mandibular structures like T-ribs and VA suggest they originate from different primordia.

\section{(4) Maternal genes}

Mutants of the maternal gene torso have been described as lacking the anteriormost part of the head, including the labrum (Schupbach and Wieshaus, 1986). HSU tor $^{-}$ embryos show a transformed head in which the region of naked cuticle and the epistomal sclerite are missing, so that the $\mathrm{Cl}$ belt is the most anterior structure present. This is consistent with previous observations (Nusslein-Volhard et al. 1987) that torso mutants eliminate the non-segmented part of the head and indicates that the $\mathrm{C} 1$ belt marks the limit of the metamerized body.

\section{Discussion}

The inappropriate expression of some homeotic genes prevents the involution of the head

The involution of the head is a major feature of cephalogenesis; it comprises a complex pattern of movements involving the procephalon and the gnathal segments. This phenomenon is probably one component of the identity conferred by the set of homeotic or selectors genes responsible of the development of the head segments.

Mutations in trans acting genes of the $P c$-type, known to activate the homeotic genes out of context (Struhl and White, 1985; Struhl and Akam, 1985; Kuziora and McGinnis, 1988b) prevent head involution to a variable degree (Struhl, 1983; Sato and Denell, 1985). Homeotic genes like Antp (Gibson and Gehring, 1988) also cause 
the same effect if they are activated in the cephalic primordia during the extended germ band period. The inhibition of head involution seen in these embryos is accompanied by a homeotic transformation of the head segments.

In our experiments, we have expressed one of the $U b x$ proteins under heat-shock control and found the same result if the $U b x$ homeoprotein is expressed in the embryonic head primordia between 3 and $8 \mathrm{~h}$ of development. This coincides with the time when the $U b x$ protein is most effective in producing abdominal transformations in the head segments. Similarly, the Antp protein has the strongest effect at the same time (Gibson and Gehring, 1988; Urquía and Morata, unpublished data), suggesting that thoracic and abdominal transformations and the failure of head involution are linked phenomena. However, in the cases of genes specifying gnathal segment development like $S c r$ (in part) or $D f d$, their overall expression has little effect on the involution of the head (Kuziora and McGinnis, 1988b; Gibson et al. 1990), probably because these genes specify identities of segments that are normally involved in the process.

$A$ priori there is no reason why the inappropriate expression of a homeotic gene like $U b x$ or Antp should result in the inhibition of the process of head involution. We think that the reason lies in the phenomenon of functional hierarchy of the homeotic genes (Struhl, 1983; Gonzalez-Reyes et al. 1990). The involution of the head probably depends on the function of some specific homeotic genes that activate a special set of subsidiary genes. When the products of genes (e.g. Antp or $U b x$ ) normally acting in more posterior regions, are present in the head primordia, by virtue of the functional hierarchy between the homeotic products they establish their own developmental programs and suppress those of the head genes. As a result, the cephalic primordia develop like thoracic (Antp) or abdominal (Ubx) primordia, which do not invaginate. Thus, the suppression of head involution observed in our experiments and in genetic combinations producing inappropriate expression of homeotic genes (e.g. esc or $P c$ mutations), is probably a consequence of the functional hierarchy between homeotic genes.

\section{The principal parts of the head}

Our results bear on the question of the original subdivision of the larval head. Morphologically it is made of two parts separated by the cephalic furrow, the gnathocephalon and the procephalon. The former is metamerized like the thorax and the abdomen, while there is very little evidence that the procephalon is organized in this manner, even though it forms a large part of the embryonic head.

Our results show that the entire head is transformed by $U b x$ into three A1-like segments. Two of the transformed primordia, $\mathrm{C} 2$ and $\mathrm{C} 3$, correspond to the maxillary and labial segments, part of the gnathocephalon, whereas the region including part of the mandibular segment and the entire procephalon only produces C1, a complex denticle belt. The experiments with btd and $e m s$ map the origin of $\mathrm{C} 1$ to the very anterior part of the procephalon and also indicate that the contribution of the mandibular, intercalary and antennal segments to it is small.

The $\mathrm{C} 1$ belt is very different from $\mathrm{C} 2$ and $\mathrm{C} 3$. As illustrated in Fig. 2, its structure and disposition of its elements is very distinctive. Also, unlike the $C 2$ and $C 3$ that derive from single segmental or parasegmental primordia, it most probably results from the fusion of several procephalic ones. It also requires less amount of $U b x$ product to be transformed and has different temporal requirements.

All these observations point to a different response of the procephalon and gnathocephalon to the presence of the $U b x$ protein. In our view, however, the critical aspect for this differential behavior is not membership of the procephalon or the gnathocephalon - these are purely morphological distinctions - but whether a primordium belongs to the parasegmental trunk (parasegments 1 to 15 ) or to the regions anterior or (possibly) posterior to it. In parasegments $1\left(\mathrm{Md}_{\mathrm{p}}-\mathrm{Mx}_{\mathrm{a}}\right)$ and 2 $\left(\mathrm{Mx}_{\mathrm{p}}-\mathrm{Li}_{\mathrm{a}}\right)$, the inappropriate expression of $U b x$ produces the expected transformation into A1 according to the functional hierarchy of the homeotic genes (Struhl, 1983): the two anterior compartments $\mathrm{Mx}_{\mathrm{a}}$ and $\mathrm{Li}_{\mathrm{a}}$ are transformed into A1-like denticle belts. It is noteworthy that the anterior region of the mandibular lobe, located anterior to the parasegment 1 , is apparently not homologous to an anterior compartment, for if so it would have produced another A1-like belt.

We think that the region located anterior to the parasegmental trunk is fundamentally different from that belonging to it. The two regions develop by different developmental mechanisms and consequently have different nature and properties. This is indicated by several arguments. (1) pair-rule genes like $f t z$ and eve are expressed in the parasegmental trunk region in the usual stripe fashion, but are not expressed in the region anterior to it. This is significant as these genes are thought to be of paramount importance in the definition of metameres (Lawrence et al. 1987). Therefore, whatever system is used to create the anterior cephalic metameres does not employ the same genetic operation as in the rest of the body. (2) polarity genes like engrailed (Dinardo et al. 1985), wingless (Van den Heuvel et al. 1989) and patched (I. Guerrero, personal communication; Nakano et al. 1989; Hooper and Scott, 1989) are also differently expressed in the two regions. (3) As we have shown, the two regions respond differently to the presence of the $U b x$ product.

Significantly, another region, the telson, located at the opposite pole of the body, also appears to lack the metameric organization of the central part of the body (Anderson, 1972).

In a recent review on the organization of the head, Cohen and Jurgens (1991), point out a sharp evolutionary distinction between the procephalic and gnathal regions and argue that the genetic specification of the procephalic segments is very different from that of the trunk segments.

All the previous arguments suggest that the body of 
Drosophila can be subdivided into three quite distinct parts: the parasegmental trunk and the two regions flanking it at either side. The parasegmental trunk is the largest part of the body and is formed by the chain of parasegments 1-15 generated by the concerted action of maternal and segmentation genes. Its anterior limit is defined by the first stripe of engrailed and the anterior border of eve, and corresponds to the posterior compartment of the mandibular segment. Morphologically it is near but not at the cephalic furrow. The posterior limit appears to be defined by the posterior border of $f t z$ and the anterior one of forked head (Lawrence et al. 1987; Casanova, 1990).

The two regions outside the trunk are specified by a different and essentially unknown mechanism involving different sets of genes in which pair-rule genes like ftz and $e v e$ are conspicuously lacking (Cohen and Jürgens, 1990 ) and polarity genes are expressed differentially. Since these regions are genetically built by different genetic mechanisms, it is not surprising that the rules governing the expression of the homeotic genes in the parasegmental trunk, for example, that of the functional hierarchy correlating with spatial expression (Struhl, 1983), do not apply to the anterior head.

\section{Differences in the process of determination between} the head and the thorax

Even though the three cephalic primordia respond to the presence of $U b x$ protein in the same qualitative manner as the thorax, e.g. they develop like the A1 segment, there are differences to the thorax, and also between themselves, worth mentioning. One difference is that in the thorax, all the transformations, whether partial or complete, are equal in all three segments. The head segments, on the contrary, respond in a differential and specific manner to the heat shock. The $\mathrm{C} 1$ primordium always shows transformation toward abdominal development when the heat shock is given to embryos from 3 to $6 \mathrm{~h}$ of age, but not if they are of $9 \mathrm{~h}$ or older. Given the duration of high levels of $U b x$ protein after the end of the treatment, approximately $4 \mathrm{~h}$ (González-Reyes and Morata, 1990), it seems that the presence of ectopic $U b x$ protein during the period of $6-7 \mathrm{~h}$ of age is sufficient to induce the homeotic transformation in this primordium. The $\mathrm{C} 2$ segment is different in that it requires a longer and later duration of the $U b x$ protein; a heat shock given to $5 \mathrm{~h}$ embryos produces the transformation, but not if they are of $3 \mathrm{~h}$, thus the ectopic protein has to be present from 6 to $10 \mathrm{~h}$ of development. Finally, the abdominal transformation of the C3 primordium requires a multiple pulse treatment ensuring high levels of $U b x$ protein from 5 to $10 \mathrm{~h}$. We do not know the reasons for these differences, but it is clear that in some aspects the timing of developmental events in the head segments is differs within the three cephalic primordia and is also different from the thorax.

There is another aspect in which we observe a clear cut difference between head segments and the rest: this is the distinction between the dorsal and ventral derivatives. In the thorax and abdomen each segment contains a group of ventral denticles and another of dorsal spinules, whereas in the HSU transformed head segments, there are three ventral belts and only one group of dorsal spinules. Either two dorsal primordia are missing in the head segments, or they are fused. This second possibility is in our opinion the more likely since we often observe that $\mathrm{C} 1$ and $\mathrm{C} 2$ denticle belts are connected to the single group of dorsal spinules (Fig. 2).

We thank Peter Lawrence, Ernesto Sanchez-Herrero and Jordi Casanova for their comments and constructive criticisms of the manuscript. This work has been supported by a grant of the Direccion General de Investigacion Cientifica y tecnica and by a institucional grant of the Fundacion Ramon Areces.

\section{References}

Aкам, M. (1987). The molecular basis for metameric pattern in the Drosophila embryo. Development 101, 1-22.

Anderson, D. T. (1972). The Development of Holometabolous Insects. London and New York: Academic Press.

Anderson, K. V., Júrgens, G. and Nússlein-Volhard, C. (1985). Establishment of dorso-ventral polarity in the Drosophilo embryo: genetic studies on the role of the Toll gene product. Cell 42, 779-789.

BAKER, N. E. (1987). Molecular cloning of sequences from wingless, a segment polarity gene in Drosophila: The spatial distribution of transcript in embryos. EMBO J. 6, 1765-1773.

Campos-Ortega, J. A. and Hartenstein, V. (1985). The Embryonic Development of Drosophila melanogaster. Berlin: Springer-Verlag.

Casanova, J. (1990). Pattern formation under the control of the terminal system in the Drosophila embryo. Development 110 , $621-628$.

Casanova, J., Sánchez-Herrero and Morata, G. (1986). Identification and characterization of a parasegment specific regulatory element of the $A b d o m i n a l-B$ gene of Drosophila. Cell 47, 627-636.

Cohen, S. M. And JUrgens, G. (1990). Mediation of Drosophila head development by gap-like segmentation genes. Nature 346, $482-485$.

Cohen, S. M. and Jurgens, G. (1991). Drosophila headlines. Trends Genet 7, 267.

Dinardo, S, , Kuner, J. M., Theis, J., O'Farrell, J. and O'Farrell, P. H. (1985). Development of embryonic pattern in $D$. melanogaster as revealed by accumulation of the nuclear engrailed protein. Cell 43, 59-69.

Driever, W., Thoma, G. and Nússlein-Volhard, C. (1989). Determination of spatial domains of zygotic gene expression in the Drosophila embryo by the affinity of binding sites for the bicoid morphogen. Nature 340, 363-367.

Finkelstein, R. And Perrmon, R. (1990). The orthodenticle gene is regulated by bicoid and torso and specifies Drosophila head development. Nature 346, 485-488.

Gibson, G. AND Gehring, W. J. (1988). Head and thoracic transformations caused by ectopic expression of Antennapedia during Drosophila development. Development 102, 657-675.

Gibson, G., Schier, A., LeMotie, P. and Gehring, W. J. (1990). The specifities of Sex combs reduced and Antennapedia are defined by a distinct portion of each protein that includes the homeodomain. Cell 62, 1087-1103.

Gonzalez-Reyes, A., Urquia, N., Gehring, W. J., Struhl, G. AND Morata, G. (1990). Are cross-regulatory interactions between homeotic genes functionally significant? Nature 334, $78-80$.

González-Reyes, A. And Morata, G. (1990). The development effect of overexpressing a $U b x$ product in Drosophila embryos is dependent on its interactions with other homeotic products. Cell 61, 515-522. 
Hazelrigg, T. and Kaufman, T. C. (1983). Revertants of dominant mutations associated with the Antennapedia gene complex of Drosophila melanogaster: cytology and genetics. Genetics 105, 581-600.

HoOper, J. E. AND ScotT, M. P. (1989). The Drosophila patched gene encodes a putative membrane protein required for segmental patterning. Cell 59, 751-765.

Ingham, P. W. (1988). The molecular genetics of embryonic pattern formation in Drosophila. Nature 335, 25-34.

INGHAM, P. W., Howard, K. R. AND ISH-Horowicz, D. (1985). Transcription pattern of the Drosophila gene hairy. Nature 318, 439-445.

Jurgens, G., Lehman, R., Schardin, M. and Nússlein-Volhard, C. (1986). Segmental organization of the head and embryo of Drosophila melanogaster. Roux's Arch. devl. Biol. 195, 359-377.

Kaufman, T. C., Seeger, M. A. and Olsen, G. (1990).

Molecular and genetic organization of the Antennapedia gene complex of Drosophila melanogaster. Advances in Genetics. 27, 309-361.

Kornfeld, K., Saint, R. B., Beachy, P. A., Harte, P. J., Peattie, D. A. AND Hogness, D. S. (1989). Structure and expression of a family of Ultrabithorax mRNAs generated by alternative splicing and polyadenilation in Drosophila. Genes Dev. 3, 243-258.

Kuziora, M. A. AND McGinnis, W. (1988a). Autoregulation of a Drosophila homeotic selector gene. Cell 55, 477-485.

Kuziora, M. A. AND MCGinNis, W. (1988b). Different transcripts of the Drosophila $A b d-B$ gene correlate with distinct genetic sub-functions. $E M B O$ J. 7, 3233-3244.

LaWrence, P. A., Johnson, P., McDonald, P. and Struhl, G. (1987). Borders of parasegments in Drosophila embryos are delimited by the fushi tarazu and even-skipped genes. Nature 328, 440-442.

LeMotte, P., Kuroiwa, A., Fessler, L. I. and Gehring, W. (1989). The homotic gene Sex comb Reduced of Drosophila: gene structure and embryonic expression. EMBO J. 8, 219-227.

ManN, R. S. ANd Hogness, D. S. (1990). Functional dissection of Ultrabithorax proteins in D. melanogaster. Cell 60, 597-610.

McGinnis, W., Jack, T., Chadwick, R., Regulski, M., Bergson, C., McGinnis, N. ANd Kuziora, M. A. (1990). Establishment and maintenance of position-specific expression of the Drosophila homeotic selector gene Deformed. In Advances in Genetics Vol. 27 (ed. TRF Wright), pp. 363-402. San Diego: Academic Press.

Merrill, V., Turner, F. R. and Kaufman, T. C. (1987). A genetic and developmental analysis of mutations in the Deformed locus in Drosophlla melanogaster. Devl Biol. 122 379-395.

Mlodzik, M., Fuose, A. And Gehring, W. J. (1988). Molecular structure and spatial expression of a homeobox gene from the labial region of the Antennapedia-complex. EMBO J.7, $2569-2578$.

Nakano, Y., Guerrero, I., Hidalgo, A., Taylor, A., Whittle, J. R. S. AND INGham, P. W. (1989). A protein with several possible membrane-spanning domains encoded by the Drosophila segment polarity gene patched. Nature 341, 508-513.

Nússlein-Volmard, C. H., Frohnhofer, H. G. and LehmanN, R. (1987). Determination of anteroposterior polarity in Drosophila. Science 238, 1675-1681.

Sato, T. and Denell, R. E. (1985). Homeosis in Drosophila: anterior and posterior transformations of Polycomb lethal embryos. Devl Biol. 110, 53-64.

Schupbach, T. and Wieschaus, E. (1986). Maternal-effect mutations altering the anterior-posterior pattern of the Drosophila embryos. Roux's Arch devl Bıol. 195, 302-317.

STRUHL, G. (1981a). Anterior and posterior compartments in the proboscis of Drosophila. Devl Biol. 84, 372-385.

STRUHL, G. (1981b). A homeotic mutation transforming leg to antenna in Drosophila. Nature 292, 635-638.

STRUHL, G. (1981c). A gene product required for correct initiation of segmental determination in Drosophila. Nature 293, 36-41.

STRUHL, G. (1982). Genes controlling segmental specification in the Drosophila thorax. Proc. natn. Acad. Sci. U.S.A. 79, $7380-7384$.

STRUHL, G. (1983). Role of esc product in ensuring the selective expression of segment-specific genes in Drosophila. J. Embryol. exp. Morph. 76, 297-331.

STRUHL, G. (1984). Splitting the bithorax complex of Drosophila. Nature 308, 454-457.

STRUHL, G. (1985). Near-reciprocal phenotypes caused by inactivation or indiscriminate expression of the Drosophila segmentation gene ftz. Nature 318, 677-680.

Struhl, G. and AKam, M. (1985). Altered distribution of Ultrabithorax transcripts in extra sex combs mutant embryos of Drosophila. EMBO J. 4, 3259-3264.

Struhl, G. and Whrte, R. A. H. (1985). Regulation of the Ultrabithorax gene of Drosophila by other bithorax complex genes. Cell 43, 507-519.

Technau, G. M. and Campos-Ortega, J. A. (1985). Fate-mapping in wild-type Drosophila melanogaster II. Injections of horseradish peroxidase in cells of the early gastrula stage. Roux's Arch. devl Biol 194, 196-212.

Turner, R. F. And Mahowald, A. P. (1979). Scanning electron microscopy of Drosophila melanogaster embryogenesis. Devl Biol. 68, 96-109.

Van den Heuvel, M., Nusse, R., Johnston, P. and Lawrence, P. A. (1989). Distribution of the wingless gene product in Drosophila embryos: A protein involved in cell-cell communication. Cell 59, 739-749.

Wakimoto, B. AND KaUfman, T. C. (1981). Analysis of larval segmentation in lethal phenotypes associated with the Antennapeda gene complex in Drosophila melanogaster. Devl Biol. 81, 51-64. 